\title{
Relevance of new psychotropic drugs for the neurologist
}

\section{A E Hensiek, M R Trimble}

\section{Clinicians can now select psychotropic agents from a wide choice}

$\square$ he discovery of neuroleptic and antidepressant drugs about 50 years ago marked a breakthrough in pharmacotherapeutics, which has revolutionised the therapy of many neuropsychiatric conditions. The efficacy of the early and then standard agents in alleviating depressive and psychotic symptoms and preventing their reoccurrence has been established in numerous trials, but other factors limit their utility. These include the facts that not all patients respond to treatment, and that they tend to often have an unacceptable incidence of side effects, many of which are neurological in nature-such as parkinsonism, dystonia, tardive dyskinesia, and seizures.

In an effort to match improved therapeutic efficiency with a better side effect profile, various new antidepressant and antipsychotic drugs have recently been developed. These are becoming widely used and their introduction may have important consequences for neurological practice.

\section{ANTIPSYCHOTIC DRUGS}

According to the dopamine hypothesis for schizophrenia, limbic D2 receptor blockade is essential for a drug to have antipsychotic activity. ${ }^{1}$ Classic neuroleptic drugs, such as haloperidol, antagonise dopamine D2 receptors and their clinical efficacy correlates with inhibitory activity at these receptor subtypes. Haloperidol leads to parkinsonism in $15 \%-45 \%$ of treated schizophrenic patients. ${ }^{2}$

The development of clozapine with properties differing from traditional neuroleptic agents has heralded the era of "atypical" antipsychotic drugs which are claimed to have improved tolerability and effectiveness compared with conventional neuroleptic drugs. The effectiveness of clozapine in treating patients with schizophrenia refractory to other medications, ${ }^{3}$ coupled with a low incidence of extrapyramidal side effects, has been attributed to a unique receptor profile and marked a major advance in psychopharmacotherapy. However, therapy with clozapine is limited by its potential for serious adverse effects, in particular the induction of agranulocytosis in $1 \%-2 \%$ of patients and it is therefore considered a second line therapy. Patients treated with clozapine initially need weekly blood count screening, which is reduced to fortnightly after 18 weeks and then to monthly after 1 year of satisfactory blood results. All patients on clozapine have to be registered with the Clozaril Patient Monitoring Service. ${ }^{4}$ Other disadvantages of clozapine include its propensity to cause worsening confusion due to anticholinergic properties, and its potential to induce seizures. ${ }^{6}$ Seizures are seen with clozapine in up to $5 \%$ of patients with doses of $600 \mathrm{mg}$ or more, but even on lower doses EEG changes may be noted. Generalised tonic-clonic and myoclonic seizures are the most frequent reported.

The new generation of antipsychotic drugs includes those that have a similar receptor profile as clozapine, such as olanzapine and quetiapine, and others, such as risperidone.

The term "atypical" relates to their low propensity to cause extrapyramidal side effects, and they have minimal effects on serum prolactin concentrations. ${ }^{7}$ The mechanism of this "atypicality" seems to relate to different receptor profiles - that is, broader receptor profiles or more selective dopamine receptor binding. Several mechanisms have been proposed.

Some atypical antipsychotic drugs occupy lower levels of D2 receptors (for example, $20 \%-50 \%$ for clozapine) than the classic antipsychotic drugs, which occupy between $80 \%$ and $90 \% .{ }^{8}$ This effect is dose dependent and it has been proposed that it may be partly due to rapid displacement of these agents from the receptors by endogenous dopaminethat is, they are more loosely bound. ${ }^{9}$ The D2 receptor occupancy of olanzapine and risperidone is similar to traditional neuroleptic drugs at clinically used doses.

Newer antipsychotic agents generally have a lower affinity for striatal D2 receptors and some preferentially bind to limbic rather than striatal D2 receptors (for example, clozapine, amisulpiride). ${ }^{10}{ }^{11}$ A possible explanation for this phenomenon would be that higher output of endogenous dopamine in the striatum displaces more D2 bound drug, compared with low output in the limbic cortex. ${ }^{12}$ Of all the newer drugs, clozapine is the only one that seems not to bind to the core of the nucleus accumbens.

Other relevant mechanisms might include a high affinity for muscarinic $\mathrm{Ml}$ receptors of some agents (for example, clozapine, olanzapine), that make them potent anticholinergic drugs. It has been argued that the simultaneous blockade of D2 and Ml receptors by these drugs may be much more effective in preventing parkinsonism than nonsimultaneous blockade. ${ }^{9}$

Several atypical antipsychotic drugs also have a higher affinity for cortical serotonin $(5-\mathrm{HT})$ receptors rather than striatal D2 receptors. The blockade of 5-HT receptors could explain the lack of parkinsonian side effects, as neuroleptic induced catalepsy can be reduced by serotonin antagonists such as mianserin or cyproheptadine or by lesions of serotonin nuclei. Reduced serotonin moderates the reduction in dopaminergic function, resulting from blockade of D2 receptors. ${ }^{13}$ It seems, however, that an at least 10 -fold greater affinity for 5-HT than for D2 receptors is required to achieve this effect (as with clozapine or risperidone). ${ }^{\text {? }}$

A strong affinity to the dopamine D4 receptor has been proposed to be relevant in the atypical action of some new antipsychotic drugs, in particular clozapine. The therapeutic dose of clozapine correlates well with its dissociation constant at D4, and clozapine has a higher affinity for D4 rather than D2. The D4 receptor belongs to the $\mathrm{D} 2$ receptor family and it has been suggested that it may be a relevant receptor for mediating antipsychotic action. ${ }^{14} \mathrm{D} 4$ receptors seem to be restricted to the limbic region, which could account for the reduced likelihood of clozapine to produce extrapyramidal side effects. ${ }^{15}$

Many mixed atypical compounds act on various other receptors-for example, histamine, sigma, or adrenergic receptors. In addition they influence GABA and neuropeptides including neurotensin, metencephalin, and cholecystokinin. Even though several hypotheses for a potentially important role of these actions have been proposed, the relevance in terms of therapeutic and adverse effects of treatment is not known.

Despite their common features, each of the atypical antipsychotic drugs has a different relative affinity for the various receptors, which accounts for their individual properties. Table l summarises the receptor profiles of haloperidol and various atypical antipsychotic agents.

Table 2 shows results of animal studies, which have measured the potential of different antipsychotic drugs to generate catalepsy and their effect on conditioned avoidance, which is sensitive for 
Table 1 Receptor binding profiles of antipsychotic drugs ${ }^{16 *}$

\begin{tabular}{lllllllllll}
\hline \multirow{8}{*}{ Drug } & \multicolumn{1}{c}{ Affinity for receptor (Ki (nmol/I)) } \\
\cline { 2 - 10 } & D1 & D2 & D4 & $\alpha 1$ & $\alpha 2$ & H1 & 5-HT2a & 5-HT2c & M \\
\hline Haloperidol & 25 & 1 & 5 & 46 & 360 & $>1000$ & 78 & $>1000$ & 570 \\
Clozapine & 85 & 126 & 9 & 7 & 8 & 6 & 12 & 8 & 1.0 \\
Risperidone & 75 & 3 & 7 & 2 & 3 & 155 & 0.6 & 26 & $>1000$ \\
Olanzapine & 31 & 112 & 27 & 19 & 228 & 7 & 4 & 11 & 2.1 \\
Quetiapine & 455 & 160 & NA & 7 & 87 & 11 & 220 & 615 & 56 \\
\hline
\end{tabular}

*Information from premarketing trials and product monograph.

D1, D2, D4 , dopamine receptors; $\alpha 1, \alpha 2$, adrenergic receptors; $M$, muscarinergic receptor; 5-HT2a,

5 -HT2c, serotonin receptors; $H$, Histamine receptors.

predicting ratios for activities against extrapyramidal side effects. ${ }^{16}$

Clinical trials concerning the rate of occurrence of drug induced movement disorders of different new antipsychotic agents have been difficult to interpret and compare, because often patients have been on conventional antipsychotic drugs until shortly before entering a trial. Clozapine has been most extensively studied and several reports indicate that it improves or halts progression of tardive dyskinesia, chronic akathisia, and drug induced parkinsonism. ${ }^{17}$ There have been no reports of cases of tardive dyskinesia in patients who have only taken clozapine, but no other antipsychotic drug.

Reports on the use of risperidone for patients with tardive dyskinesia are unclear, some suggesting induction and others suppression. Parkinsonism and akathisia have been reported to occur after risperidone ${ }^{18}$ and it seems to cause more extrapyramidal side effects than clozapine. The pharmacological profile of risperidone differs from clozapine, in that risperidone has a much higher affinity for D2 receptors and less anticholinergic properties.

Olanzapine has a similar pharmacological profile to clozapine; however, it has a slightly higher affinity to D2 and 5-HT receptors. The potential of olanzapine to cause extrapyramidal side effects is probably intermediate between clozapine and risperidone. ${ }^{19}$ Quetiapine, which has low D2 and also low 5-HT affinity, causes few, if any extrapyramidal side effects. ${ }^{20}$
Amisulpiride, which is a recently licensed sulpiride analogue, differs from other agents in that it exhibits selective affinity for D2 and D3 receptors and is devoid of affinity for other dopamine receptor subtypes, serotinergic or cholinergic receptors. ${ }^{11}$ The incidence of extrapyramidal side effects is dose dependent but lower compared with conventional antipsychotic drugs. ${ }^{2}$ Data on comparison with other newer agents are limited.

Because of their lesser potential to produce parkinsonism, atypical neuroleptic drugs have not only gained growing importance in the therapy of schizophrenia, but have also taken on a central role in the management of dopaminergic psychosis in extrapyramidal disorders such as Parkinson's disease or related conditions such as Lewy body dementia. Psychotic symptoms occur as a complication of drug therapy in about one fifth of patients with Parkinson's disease $^{21}$ and commonly in Lewy body dementia. Although it may be possible in some patients to reduce antiparkinsonian therapy, this usually makes parkinsonism worse and may not be well tolerated. In this situation the use of atypical neuroleptic drugs is indicated.

The benefits and limitations of different atypical neuroleptic drugs in dopaminergic psychosis correspond to what would be expected from data of extrapyramidal symptoms in nonparkinsonian patients. Clozapine, which seems to have least extrapyramidal side effects in non-parkinsonian patients, has been most extensively studied for treat- ment of psychosis in Parkinson's disease. All published trials have been positive, suggesting good antipsychotic activity without worsening of parkinsonism. Clozapine seems to ameliorate psychosis in Parkinson's disease at much lower dosages than those required for schizophrenia. ${ }^{22}{ }^{23}$ It has been suggested that clozapine may also have a beneficial effect on other behavioural symptoms of Parkinson's disease-for example, sleep disturbance, anxiety, and depression. In addition there have been reports of a beneficial effect of clozapine on parkinsonian tremor. ${ }^{24}$

Reports on the use of risperidone in treatment of dopaminergic psychosis have been slightly conflicting. Even though some trials show a beneficial effect on relieving psychotic symptoms, this has often been associated with a worsening of extrapyramidal symptoms or confusion. ${ }^{25}$ Similar to reports on nonparkinsonian patients, the effect of olanzapine in treating dopaminergic psychosis seems to lie between that of clozapine and risperidone. Whereas olanzapine seems to be effective in treating psychosis in parkinsonian patients, there have been some reports of worsening in motor function. ${ }^{26}$ Others, however, report no change of extrapyramidal symptoms. ${ }^{27}$ Data on the use of quetiapine in Parkinson's disease are limited, although several studies have shown improvement of psychosis without worsening of parkinsonism. ${ }^{28}{ }^{29}$ There are only limited data available on the use of amisulpride in patients with extrapyramidal disorders.

\begin{tabular}{|c|c|c|}
\hline Drug & $\begin{array}{l}\text { Effect on conditioned avoidance in } \\
\text { rats }(\operatorname{ED} 50(\mathrm{mg} / \mathrm{kg}))\end{array}$ & Catalepsy scores in rats (ED50 $(\mathrm{mg} / \mathrm{kg}))$ \\
\hline Haloperidol & 0.28 & 0.74 \\
\hline Clozapine & 33.5 & $>8$ \\
\hline Risperidone & 1.3 & 4.3 \\
\hline Olanzapine & 5.6 & 23 \\
\hline Quetiapine & 108 & $\begin{array}{l}\text { ( } 80 \mathrm{mg} \text { quetiapine produces } 37.9 \mathrm{~s} \text { catalepsy } \\
\text { compared with } 36.5 \mathrm{~s} \text { for } 4 \mathrm{mg} \text { haloperidol and } 9.5 \\
\mathrm{~s} \text { for } 80 \mathrm{mg} \text { clozapine) }\end{array}$ \\
\hline
\end{tabular}


Table 3 Side effects associated with action on different receptors

\begin{tabular}{ll}
\hline Receptor system & Effects \\
\hline Blockade of $\alpha 1$ adrenergic receptors & Postural hypotension, reflex tachycardia \\
Stimulation of serotonin 5-HT1 receptors & Antidepressant, anxiolytic effect, hypophagia \\
Stimulation of serotonin 5-HT2 receptors & Insomnia, sexual dysfunction, agitation \\
Stimulation of serotonin 5-HT3 receptors & Gastrointestinal effects \\
Blockade of $\mathrm{M1}$ muscarine receptors & Dry mouth, confusion, tachycardia \\
& Urinary retention \\
Blockade of H1 histamine receptors & Sedation, weight gain \\
\hline
\end{tabular}

\section{ANTIDEPRESSANT DRUGS}

The development of antidepressant drugs represents another important advance in psychopharmacology. The lifetime rates for major depression are between $3 \%$ and $19 \%^{30}$-a number that is probably higher for patients with neurological disease (for example, $25 \%-60 \%$ in patients with medically intractable epilepsy $\left.{ }^{31}\right)$. The original monoamine hypotheses suggested that depression is due to deficiency of one or another of three monoamines-namely serotonin, noradrenaline, and/or dopamine, ${ }^{32} 33$ and it has stood the test of time.

The almost unsurpassed efficacy of tricyclic antidepressant drugs (TCAs) is probably the result of their non-selective interaction with these monoaminergic neurotransmitters. However, their action on these and other transmitter systems (for example, cholinergic, histaminergic) produces a wide range of clinically relevant side effects, including cardiotoxicity and the occurrence of spontaneous seizures. ${ }^{34}$ This is relevant for any patient in whom the seizure threshold may be reduced. The exact neurotransmitter mechanisms underlying the proconvulsant effect are unclear. ${ }^{35}$

Early studies reported seizures in 3\% to $4 \%$ of patients receiving TCAs, ${ }^{36}$ however many of these patients had predisposing factors. More recent studies reported rates of less than $1 \%$ for patients with no risk factors on therapeutic doses. ${ }^{37} 38$ The risk of seizures with TCAs is dose related and rises with increased plasma concentrations. Reviews of patients who have taken overdoses of TCAs report seizures in $3 \%-8 \%$. $^{39}$

Selective serotonin reuptake inhibitors (SSRIs), which were introduced in the late 1980s are chemically unrelated to tricyclics and tetracyclics and have a more selective effect on the reuptake of serotonin.$^{40}$ The currently available preparations are citalopram, fluoxetine, fluvoxamine, paroxetine, and sertraline. Citalopram is the most selective of the SSRIs, and it inhibits serotonin reuptake 3000 times more than noradrenaline (norepinephrine) reuptake and 22000 times more than dopamine. ${ }^{41}$ The SSRIs are now the most widely prescribed antidepressant drugs. They are better tolerated, safer in overdose, and have a lower seizure risk compared with tricyclic drugs. $^{42}$ However, there are some case reports of patients without predisposing factors, who have had seizures on therapeutic doses of SSRIs. Additional side effects include anxiety, sleep disturbance, sexual dysfunction, and gastrointestinal disturbance, which have been attributed to the action of increased serotonin concentrations on the $5-\mathrm{H}-2$ and 5-HT3 receptor subtypes. ${ }^{43}$ The SSRIs can also provoke extrapyramidal disorders including akathisia and dystonias. ${ }^{44}$

The latest generation of antidepressant drugs has been developed to derive their therapeutic benefits from tailormade action on specific receptors, as a basis for efficacy with better tolerability. ${ }^{45}$

Reboxetine is a highly selective noradrenaline reuptake inhibitor (NARI) with a low affinity to histamine, cholinergic, dopaminergic, and $\alpha \mathrm{l}$-adrenergic receptors. It has minimal interaction with the serotinergic system, which mediates side effects such as nausea or sexual dysfunction. ${ }^{46}$ Reboxetine has been shown to be as equally effective as imipramine and more effective than fluoxetine in treating severe depression, ${ }^{47}$ but is better tolerated compared with first generation antidepressant drugs.

Venlafaxine is a serotoninnoradrenaline reuptake inhibitor (SNRI), similar to first generation antidepressant drugs. It does not, however, interact with adrenergic, histaminergic, or cholinergic receptors, avoiding the side effects associated with activity on these receptor systems. ${ }^{48}$ Several studies have indicated at least equal and occasionally superior effectiveness of venlafaxine compared

\begin{tabular}{|c|c|c|c|c|c|c|c|}
\hline \multirow[t]{2}{*}{ Drug } & \multicolumn{6}{|c|}{ Action on receptor : } & \multirow[t]{2}{*}{ Seizures/epilepsy } \\
\hline & $\mathrm{HI}$ & Ml & NA & 5-HTl & 5-HT2 & $5-\mathrm{HT} 3$ & \\
\hline Imipramine & - & - & + & + & + & + & $\begin{array}{l}0.1-4 \%{ }^{37-39} \\
\text { In overdose }{ }^{36} \text { : } \\
3.8-8 \%\end{array}$ \\
\hline Paroxetine ${ }^{6566}$ & 0 & 0 & 0 & + & + & + & $\begin{array}{l}\text { Prolonged seizures during } \mathrm{ECT}^{58} \text { : } \\
\text { In overdos } \mathrm{e}^{59} \text { : }\end{array}$ \\
\hline Sertraline ${ }^{67}$ & 0 & 0 & 0 & + & + & + & $\begin{array}{l}\text { no seizures in } 15 \text { patients with maximum dose } 850 \mathrm{mg} \\
\text { Rare reports of seizures secondary to SIADH } \\
\text { In overdose: }\end{array}$ \\
\hline Fluoxetine & 0 & 0 & 0 & + & + & + & $\begin{array}{l}\text { no seizures in } 40 \text { patients up to } 8000 \mathrm{mg}^{61} \\
<0.1 \% \%^{34 *}\end{array}$ \\
\hline Citalopram & 0 & 0 & 0 & + & + & + & $\begin{array}{l}\text { No worsening of epilepsy in } 16 \text { patients }^{62} \\
\text { In overdose } \\
1.9 \mathrm{~g}: 49 \%\end{array}$ \\
\hline Reboxetine & 0 & $0 /-$ & + & 0 & 0 & 0 & $0.13 \%{ }^{46 *}$ \\
\hline Venlafaxine & 0 & 0 & + & + & + & + & $\begin{array}{l}0.18 \% * \\
\text { In overdose }{ }^{64} \text { :Seizures in dosages over } 1000 \mathrm{mg}\end{array}$ \\
\hline Nefazodone & 0 & 0 & 0 & + & - & + & No seizures in premarketing trials, since then rare reports of convulsions* \\
\hline Mirtazepine & - & 0 & + & + & - & - & $<0.1 \%{ }^{54 *}$ \\
\hline
\end{tabular}

* Information from premarketing trials and product monograph.

0 , no or negligible effect; + , stimulation,; -, blockade; HI, histamine; Ml, muscarine; NA, noradrenaline; 5-HT1, 5-HT2, 5-HT3, serotonin receptors. 
with other antidepressant drugs (imipramine, fluoxetine). ${ }^{49}$

Nefazodone is a serotonin antagonist/ reuptake inhibitor (SARI), the most potent action of which is blockade of 5-HT2 postsynaptic receptors leading to a dual mechanism of action on the serotinergic system..$^{50}$ Noradrenaline reuptake inhibition is only minimal and there is no interaction with histamine and cholinergic receptors. Nefazodone has a good side effect profile with low rates of sexual dysfunction; it lacks cardiotoxicity in overdose, ${ }^{51}$ and seems minimally proconvulsant.

Mirtazapine is a noradrenergic and specific serotinergic antidepressant (NaSSA). It increases noradrenergic and serotinergic transmission by blockade of central $\alpha 2$ - auto and heteroreceptors. In addition it blocks 5-HT2 and 5-HT3 receptors so that the increased serotonin only stimulates 5 -HTl receptors. ${ }^{52}$ Mirtazepine is free of muscarinergic and $\alpha 1$-adrenergic side effects but acts on histamine receptors causing sedation and increased appetite. ${ }^{53}$ Mirtazapine seems safe in overdose and has a low potential to cause seizures. ${ }^{54}$ Several studies have shown equal or superior efficacy of mirtazapine compared with amitryptilline $e^{55}$ or trazodone..$^{56}$

Table 3 summarises potential side effects associated with antidepressant action on different receptor systems. Table 4 summarises receptor profiles and epileptogenic potential of several antidepressant agents.

Another problem of using antidepressant drugs in patients with epilepsy relates to their ability to alter the action of the cytochrome $P-450$ system. Inhibition of individual isoenzymes may lead to increases in serum antiepileptic drug concentrations; notably, there are interactions between carbamazepine and fluvoxamine secondary to inhibition of CYPIA2.

The past decade has witnessed the evolution of a new generation of psychotropic drugs, and clinicians can now select agents from a wide array of choices. Many of these new drugs seem to have advantages over conventional drugs in terms of efficacy and neurological and other side effects. Early results of usage of these drugs in patients with neurological disease-for example, Parkinson's disease or epilepsy-are encouraging. However, further studies are needed to confirm these benefits.

\section{$J$ Neurol Neurosurg Psychiatry}

2002;72:281-285

\section{Authors' affiliations}

\section{REFERENCES}

1 Sunahara RK, Seeman P, Van Tol HHM, et al. Dopamine Receptors and antipsychotic drug response. Br J Psych 1993;163(suppl 22):31-8.
2 Barnes TRE, McPhillips MA. Novel antipsychotics, extrapyramidal side effects and tardive dyskinesia. Int Clin Psychopharmacol 1998;13(suppl 3):S49-57.

3 Kane J, Honigfed G, Singer J, et al. Clozapine for the treatment-resistant schizophrenia. A double-blind comparison with chlorpromazine. Arch Gen Psychiatry 1988;45:189-96.

4 Kerwin R. Atypical neuroleptics. Prescriber Journal 1999;39:154-60.

5 Auzou P, Ozsancak C, Hannequin D, et al. Clozapine for the treatment of psychosis in Parkinson's disease: a review. Acta Neurol Scand 1996;94:329-36

6 Devinski O, Honigfeld G, Patin J. Clozapine-related seizures. Neurology 1991;41:369-71.

7 Waddington JL, Callaghan E. What makes an antipsychotic atypical. CNS Drugs 1997:7:341-6.

8 Kapur S, Zipursky RB, Remington G. Clinical and theoretical implications of 5-HT2 and D2 receptor occupancy of clozapine, risperidone and olanzapine. Am J Psychiatry 1999;156:286-93.

9 Seeman P. Atypical neuroleptics: role of multiple receptors, endogenous dopamine, and receptor linkage. Acta Psychchiatr Scand 1990;82(suppl 358):14-20.

10 Lieberman JA. Understanding the mechanism of action of atypical antipsychotic drugs. A review of compounds in use and development Br J Psychiatry 1993;163(suppl 22):7-18.

11 Schoenmaker $\mathrm{H}$, Claustre $\mathrm{Y}$, Fae D, et al. Neurochemical characteristics of amisulpiride, an atypical D2/D3 receptor antagonist with both presynaptic and limbic selectivity. Pharmacol Exp Ther 1997;280:83-97.

12 Seeman $\mathbf{P}$, Tallerica T. Rapid release of antipsychotic drugs from dopamine D2 receptors: an explanation for low receptor occupancy and early clinical relapse upon withdrawal of clozapine or quetiapine. Am J Psychiatry 1999; 156:876-84.

13 Richelson E. Receptor pharmacology of neuroleptics: Relation to clinical effects. J Clin Psychiatry 1999;60(suppl 10):5-14.

14 Seeman P, Guan H-C, VanTol HHM. Dopamine D4 receptors are elevated in schizophrenia. Nature 1993;365:441-5.

15 Reynolds GP. Antipsychotic drug mechanisms and neurotransmitter systems in schizophrenia Acta Psychiatr Scand 1994;89/suppl 380):36-40.

16 Kerwin R, Taylor T. New antipsychotics. CNS Drugs 1996;6:71-81.

17 Lieberman JA, Saltz BL, Johns CA, et al. The effects of clozaopine on tardive dyskinesia. $J$ Psychiatry 1991;158:503-10.

18 Rosebush PI, Mazurek MF. Neurologic side effects in neuroleptic naïve patients treated with haloperidol or risperidone. Neurology 1999;52:782-5.

19 Fernandez $\mathbf{H H}$, Friedman JH. Atypical neuroleptics in movement disorders. CNS Drugs 1999;11:467-83

20 Meats P. Quetiapine (Seroquel); an effective and well-tolerated atypical antipsychotic. International Journal of Psychiatry and Clinical Practice 1997;1:231-9.

21 Wolters EC. Dopaminergic psychosis in Parkinson's disease patients: diagnosis and treatment. Neurology 1999;53/suppl 3):S10-13.

22 Ruggieri S, De Pandis MF, Bonamartini A, et al. Low dose of clozapine in the treatment of dopaminergic psychosis in Parkinson's disease. Clin Neuropharmacol 1997;20:204-9.

23 Trosch RM, Friedman JH, Lannon MC, et al. Clozapine use in Parkinson's disease: a retrospective analysis of a large multicentred clinical experience. Mov Disord 1998;13:377-82

24 The Parkinson's Study Group. Low dose clozapine for the treatment of drug-induced psychosis in Parkinson's disease. N Engl J Med 1999;340:757-63.

25 Rich SS, Friedman JH, Ott BR. Risperidone versus clozapine in the treatment of psychosis in six patients with Parkinson's disease and other akinetic-rigid syndromes. J Clin Psychiatry 1995; 12:556-9.

26 Molho ES, Factor SA. Worsening of motor features of parkinsonism with olanzapine. Mov Disord 1999;14:1014-16.

27 Wolters EC, Jansen EN, Tuynman-Qua HG, et al. Olanzapine in the treatment of dopaminergic psychosis in patients with Parkinson's disease. Neurology 1996;47: 1085-7.

28 Targum SD, Abbott JL. Efficacy of quetiapine in Parkinson's patients with psychosis. J Clin Psychopharmacol 2000;20:54-60.

29 Fernandez HH, Friedman JH, Jacques C, et al. Quetiapine for the treatment of drug induced psychosis in Parkinson's disease. Mov Disord 1999; 14:484-7

30 Angst J. Epidemiology of depression. Psychopharmacology 1992;106:S71-4.

31 Lambert MV, Robertson MM. Depression in epilepsy: etiology, phenomenology and treatment. Epilepsia 1999;40/suppl 10): $521-47$

32 Schatzberg AF. Noradrenergic versus serotinergic antidepressants: predictors of treatment response. J Clin Psychiatry 1998;59(suppl 14):15-18.

33 Cummings JL. The neuroanatomy of depression. J Clin Psychiatry 1993;45(suppl 1 1):14-20.

34 Edwards JG, Long SK, Segwick EM, et al. Antidepressants and convulsive seizures: clinical, electroencephalographic and pharmacologic aspects. Clin Neuropharmacol 1986;4:329-60.

35 Trimble $M$. Non-monoamine oxidase inhibitor antidepressants and epilepsy: a review. Epilepsia 1978;19:241-50.

36 Blair D. Treatment of severe depression with imipramine: an investigation of 100 cases. Journal of Mental Sciences 1960;106:891-905.

37 Edwards JC. Antidepressants and convulsions. Lancet 1979;ii:1368-9.

38 Rosenstein DL, Nelson JC, Jacobs SC. Seizures associated with antidepressants. A review. J Clin Psychiatry 1993;54:289-99.

39 Stimmel GL, Dopheide JA. Psychotropic drug-induced seizures. CNS Drugs 1996;5:37-49

$40 \mathrm{Stahl} \mathrm{SM}$. Not so selective serotonin re-uptake inhibitors. Clin Psychiatry 1998;59:343-4.

41 Noble S, Benfield P. Citalopram: a review of its pharmacology, clinical efficacy and tolerability in the treatment of depression. CNS Drugs 1997;8:410-31.

42 Curran S, de Pauw K. Selecting an antidepressant for use in a patient with epilepsy. Safety considerations. Drug Saf 1998; 18:125-33.

43 Prakash SM, Gupta S. Selective serotonin re-uptake inhibitors: an update. Harvard Rev Psychiatry 1999;7:69-84.

44 Leo RJ. Movement disorders associated with the serotonin re-uptake inhibitors. J Clin Psychiatry 1996;57:449-54.

45 Feighner JP. Mechanism of action of antidepressant medications. J Clin Psychiatry 1999;60(suppl 4):4-11

46 Montgomery SA. Chairman's overview. The place of reboxetine in antidepressant therapy. J Clin Psychiatry 1998;59(suppl 14):26-9.

47 Montgomery SA. Reboxetine: additional beliefs to the depressed patients. J Psychopharmacol 1997;11(suppl):S9-15.

48 Baldwin DS. Venlafaxine. Prescriber Journal 1999;39:242-7.

49 Burnett FE, Dinan TG. The clinical effectiveness of venlafaxine in the treatment of depression. Reviews of Contemporary Pharmacotherapy 1994;9:303-20.

50 Stahl SM. Basic psychopharmacology of antidepressants, part 1: antidepressants have seven distinct mechanisms of action. J Clin Psychiatry 1998;59(suppl 4):5-14.

51 Mir S, Taylor D. The adverse effects of antidepressants (review). Curr Opin Psychiatry 1997;10:88-94. 
52 De Boer T. The pharmacological profile of mirtazepine. J Clin Psychiatry 1996;57/suppl 4):15-25.

53 Westenber HGM. Pharmacology of antidepressants: selectivity or multiplicity? J Clin Psychiatry 1999;60(suppl 17):4-8

54 Montgomery SA. Safety of mirtazepine: a review. Int Clin Psychopharmacol 1995; 10(suppl 4):37-45

55 Bremner JD. A double blind comparison of Org 3770, amitryptiline and placebo in major depression. J Clin Psychiatry 1995;56:519-26.

56 Van Moffaert M, de Wilde J, Vereeken A, et al. Mirtazepine is more effective than trazodone: a double blind controlled study on hospitalised patients with major depression. International Clinical Psychopharmacology 1995;10:3-9.

57 Owens MJ, Morgan WN, Plott SJ, et al. Neurotransmitter receptor and transporter binding profile of antidepressants and their metabolites. J Pharmacol Exper Ther 1997;283: 1305-22.

58 Curran S. Effect of paroxetine on seizure length during electroconvulsive therapy. Acta Psychiatr Scand 1995;92:239-40.

59 Boyer WF and Blumhardt CL. The safety profile of paroxetine. J Clin Psychiatry 1992;53(suppl 2):61-66r.

60 Goldstein L, Barker M, Segall F, et al. Seizure and transient SIADH associated with sertraline. Am J Psychiatry 1996;135:732.

61 Lau GT, Horowitz BZ. Sertraline overdose. Acad Emerg Med 1996;3:132-6.

62 Specchio LM, La Neve A, Spinelli A, et al. II trattamento antidepressivo con citalopram in pazienti con epilessia: dati preliminari. Boll Lega It Epil 1999;99: 187-8.

63 Personne M, Person H, Sjoeberg G. Citalopram overdose. Review of cases treated in Swedish hospitals. Lancet 1997;350:518-19.

64 White CM, Gailey RA, Levin GM, et al. Seizure resulting from a venlafaxine overdose. Ann Pharmacother 1997;31:178-80.

65 Tulloch IF, Johnson M. The pharmacologic profile of paroxetine, a new selective serotonin re-uptake inhibitor. J Clin Psychiatry 1992;53(suppl 2):7-1

66 Redrobe JP, Bourin M, Colombel MC, et al. Psychopharmacological profile of the selective serotonin re-uptake inhibitor paroxetine: implication of noradrenergic and serotinergic mechanisms. J Psychopharmacol 1998; 12:348-55

67 Murdoch D, McTavish D. Sertraline. A review of its pharmacodynamic and pharmacokinetic properties, and therapeutic potential in depression and obscessive-compulsice disorder. Drugs 1992;44:604-24.

\section{Variant Creutzfeldt-Jakob disease}

\section{R G Will}

\section{How new is new?}

f variant Creutzfeldt-Jakob disease (vCJD) is caused by bovine spongiform encephalopathy (BSE) it must be a new disease, as human exposure to the BSE agent is unlikely to have happened much before 1983. ${ }^{1}$ The study by Hillier et al (this issue, pp 304-309) 2 $^{2}$ adds significantly to the evidence supporting the hypothesis that VCJD really is a new disease, with the caveat that the study unavoidably had incomplete follow up data. No previously unrecognised cases of vCJD were found in a systematic retrospective study in Wales, which included review and restaining of available neuropathological tissue. A similar study based on death certificates in England and Wales between 1979 and 1996 also failed to identify missed cases of $\mathrm{vCJD}^{3}$ and no case with a similar neuropathological phenotype to vCJD has been identified in any country despite extensive review of archival neuropathology tissues. Although there are still doubters ${ }^{4}$ informed opinion supports the view that vCJD really is a new disease. ${ }^{5}$ It is important to recognise that the availability of stored brain samples was critical to the identification of $\mathrm{VCJD}^{7}$ and to the study of Hillier et $a l^{2}$ Defending medical activities deemed by some to be ethically controversial is essential both for research and informed clinical practice.

Although the clinical features of the first three cases of vCJD were judged to be "well within the recognised diagnostic spectrum for CJD", , the neurological phenotype of vCJD is relatively distinct from sporadic CJD and also fairly consistent between cases. ${ }^{10}$ The implication is that it is likely that cases of vCJD are being identified in life by neurologists and, assuming notification to the surveillance system, that the figures on numbers of cases of VCJD are accurate. There is a separate surveillance system for vCJD in children, ${ }^{11}$ which has led to the identification of six cases of vCJD where the patient's age was less than 16 years at onset of symptoms. The diagnosis of VCJD has been confirmed in a patient aged 74 years, $^{12}$ significantly extending the age range and raising questions about the efficiency of surveillance in elderly people. Accuracy of data on the numbers of cases of vCJD is critical to public health planning and to both short term and long range forecasts of the future of the vCJD epidemic.

Analyses of short term trends in vCJD have been published ${ }^{13}$ and currently indicate an approximate doubling in the number of cases of VCJD in the United Kingdom every 3 years. Longer term predictions of VCJD numbers have been more controversial with a wide range of future scenarios varying between a total of just over 200 cases, ${ }^{14}$ a few thousand cases $^{15}$ and over 130000 cases. $^{16}$ This variation reflects the many uncertainties about BSE and VCJD, including the extent of human exposure to BSE, the level of the species barrier between bovine and human, and variations in host susceptibility-to date all tested cases of vCJD have been homozygous for methionine at codon 129 of the prion protein gene. One important variable in all estimates of VCJD numbers is the year cases first appeared. The paper by Hillier at $a l^{2}$ provides important support to the hypothesis that vCJD is a new disease which really did first appear in the mid1990s. J Neurol Neurosurg Psychiatry
2002;72:285-286

\section{Authors' affiliations}

R G Will, National CJD Surveillance Unit, Edinburgh University (Old Pharmacy Building), Western General Hospital, Crewe Road, Edinburgh EH4 2XU, UK; r.g.will@ed.ac.uk

\section{REFERENCES}

1 Anderson RM, Donnelly CA, Ferguson NM, et al. Transmission dynamics and epidemiology of BSE in British cattle. Nature 1996;382:779-88

2 Hillier CEM, Salmon RL, Neal JW, Hilton DA Possible underascertainment of variant Creutzfeldt-Jakob disease: a systematic study J Neurol Neurosurg Psychiatry 2002;72:304-9

3 Majeed A, Lehmann P, Kirby L, et al. Extent of misclassification of death from Creutzfeldt-Jakob disease in England 1979-96: retrospective examination of clinical records. BM 2000;320: 145-7.

4 Venters GA. New variant Creutzfeldt-Jakob disease: the epidemic that never was. BM 2001;323:858-61.

5 Almond J, Pattison J. Human BSE. Nature 1997;389:437-8.

6 Collinge J. Variant Creutzfeldt-Jakob disease. Lancet 1999;354:317-23.

7 Will RG, Ironside JW, Zeidler $M$, et al. A new variant of Creutzfeldt-Jakob disease in the UK. Lancet 1996;347:921-5.

8 Warlow CP. Ethical barriers to research into diseases of the human brain. Advances in Clinical Neuroscience and rehabilitation 2001;1:10-3.

9 Grand round. Creutzfeldt-Jakob disease in a young woman. Lancet 1996;347:945-8.

10 Will RG, Zeidler M, Stewart GE, et al. Diagnosis of new variant Creutzfeldt-Jakob disease. Ann Neurol 2000;47:575-82.

11 Verity CM, Nicoll A, Will RG, et al. Variant Creutzfeldt-Jakob disease in UK children: a national surveillance study. Lancet 2000;356: 1224-7.

12 Lorains JW, Henry C, Agbumu DA, et al. Variant Creutzfeldt-Jakob disease in an elderly patient. Lancet 2001;357:1339-40. 
13 Andrews NJ, Farrington CP, Cousens SN, et al. Incidence of variant Creutzfeldt-Jakob disease in the UK. Lancet 2000;356:481-2.

14 Valleron A-J, Boelle P-Y, Will R, et al.

Estimation of epidemic size and incubation time based on age characteristics of VCJD in the United Kingdom. Science 2001;294:1726-8.

15 Huillard d'Aignaux JN, Cousens SN, Smith PG. Predictability of the UK variant
Creutzfeldt-Jakob disease epidemic. Science 2001;294:1729-31.

16 Ghani AC, Ferguson NM, Donnelly CA, et al. Predicted VCJD mortality in Great Britain. Nature 2000;406:583-4.
Dystonia

\section{Dystonia in multiple system atrophy}

\section{E Riley}

\section{Dystonia is often encountered in untreated MSA}

n this issue (pp 300-303) Boesch et al report on their experience with dystonia in multiple system atrophy (MSA). ${ }^{1}$ They correctly point out the relative neglect of dystonia in previous clinical descriptions of patients with MSA. In 1986, Adams declared that dystonia was "not part of the clinical tableau" of striatonigral degeneration, ${ }^{2}$ a quarter of a century after he described the disease. (Striatonigral degeneration corresponds to the MSA-P designation, carried by the bulk of the patients of Boesch et al, of current diagnostic classifications of MSA). Even when discussion focused on the motor problems caused by MSA, dystonia was not mentioned. These influential writings have led us to discount the likelihood of MSA causing a combination of dystonia and parkinsonism in favour of other diagnoses, such as Parkinson's disease or corticobasal degeneration.

Much as in Parkinson's disease, dystonia may be a direct manifestation of MSA or the result of treatment with dopaminergic agents. The highest previously recorded prevalence of dystonia in MSA was $12 \% .{ }^{4}$ In the current report, dystonia was documented in $46 \%$ of untreated patients with MSA. Antecollis accounted for most of the dystonia encountered in these patients, with focal limb dystonias comprising the rest. Of note, disease related focal limb dystonia improved on levodopa in five of five patients. Over $80 \%$ of patients with a predominantly parkinsonian presentation (MSA-P) enjoyed a moderate to excellent response to levodopa initially, although this was unsustained in most. Almost half of those responsive to levodopa developed drug induced cranial-cervical dystonia. Their facial predilection and their dystonic character, regardless of distribution, seem to distinguish the drug induced dyskinesias of MSA from those seen in Parkinson's disease

Boesch et al do not comment on the discrepancy between the high prevalence of dystonia in their series and the low occurrence rates in prior studies. Undoubtedly the observational meticulosity of the authors of this prospective study played a major role. It is also likely that focal dystonia is overshadowed in most patients by parkinsonism, cerebellar deficits, or corticospinal tract impairment. Nevertheless, Boesch et al have made an important contribution by determining that, if actively sought, dystonia may be one of the most common clinical features of MSA. The authors do note that some doubt was cast on the dystonic nature of antecollis in MSA in a recent report attributing the forward flexion of the neck to myopathy in extensor muscles.

The report of Boesch et al helps flesh out our knowledge regarding the clinical repertoire of MSA. It also extends previous descriptions of the response of patients with MSA to levodopa. It is a welcome addition to our expanding body of knowledge on the clinical differential diagnosis of parkinsonism.

J Neurol Neurosurg Psychiatry 2002;72:286

\section{Author's affiliations}

D E Riley, Department of Neurology, University Hospitals of Cleveland and Case Western Reserve University School of Medicine, 11100 Euclid Avenue, Cleveland, Ohio 44106, USA;

David.Riley@uhhs.com

\section{REFERENCES}

1 Boesch SM, Wenning GK, Ransmayr G, et al Dystonia in moultiple system atrophy. J Neurol Neurosurg Psychiatry 2002;72:300-3.

2 Adams RD, Salam-Adams M. Striatonigral degeneration. In: Vinken PJ, Bruyn GW, Klawans HL, eds. Extrapyramidal disorders. Amsterdam: Elsevier, 1986:205-12.

3 Quinn NP, Marsden CD. The motor disorder of multiple system atrophy. J Neurol Neurosurg Psychiatry 1993;56: 1239-42.

4 Wenning GK, Tison F, Ben Shlomo Y, et al. Multiple system atrophy: a review of 203 pathologically proven cases. Mov Disord 1997; 12:133-47.

5 Askmark H, Eeg-Olofsson K, Johansson A, et al. Parkinsonism and neck extensor myopathy: a new syndrome or coincidental findings? Arch Neurol 2001;58:232-7. 